\title{
La violencia en Cuentos completos de Arturo Martínez Galindo y Ceniza de Eliseo Pérez Cadalso
}

\author{
Emmanuel Jaén \\ Palabras Clave: $<$ Narrativa hondureña $><$ Violencia $><$ Análisis literario $>$
}

\section{Resumen}

Se aborda el tema de la violencia en dos obras de escritores hondureños del siglo XX: Cuentos completos de Arturo Martínez Galindo y Ceniza de Eliseo Pérez Cadalso. Se evidencia, en uno de los relatos más conocidos de Martínez Galindo y en varios de Pérez Cadalso, que la violencia procede de situaciones sociales que no están plenamente dilucidadas. Empero, ello permite apreciar dos aspectos del tema: primero, sus manifestaciones más execrables (el asesinato, la violación) segundo, la propuesta estética de ambos autores. El análisis psicológico y social propuesto, permite un acercamiento a las motivaciones de los personajes.

Arturo Martínez Galindo (1900-1940) fue miembro del denominado “Grupo Renovación" quiénes en la década de 1920 realizaron los primeros intentos por modernizar el cuento hondureño gracias a una serie de publicaciones como El Ateneo de Honduras y la revista Ariel de circulación internacional. El investigador Manuel Salinas Paguada señala que el cuento hondureño a partir de esta década seguiría dos vertientes claramente marcadas: el criollismo con sus variantes costumbrismo y regionalismo; y la corriente cosmopolita representada por Arturo Mejía Nieto y Arturo Martínez Galindo. ${ }^{1}$ Los cuentos de Galindo en su libro Sombra (1940) ahondaron en temas como el erotismo, la sexualidad y sus posibles desviaciones. Mujeres y hombres emocionalmente desavenidos pueblan el universo de nuestro autor y

${ }^{1}$ Paredes, Rigoberto y Salinas Paguada, Manuel, Literatura Hondureña, Editores Unidos, Tegucigalpa, Honduras, Primera Reimpresión, 1988, pp.222-223. 
únicamente en el cuento $\mathbf{L a} \mathbf{N a t i}$ aparece con claridad el tema de la violencia mediando siempre con la sexualidad.

Se señaló que la violencia en Arturo Martínez Galindo es infrecuente ya que su obra desarrolla una estética afincada en el eros y en las variaciones de la sexualidad. Sin embargo, en el relato ya citado encontramos una excepción: Octavio Fernández el protagonista, retorna a Tegucigalpa después de una larga ausencia que lo llevó a recorrer el mundo. De regreso a la patria rememora su infancia a orillas del río Grande; toma conciencia de la imperturbabilidad del tiempo de su ciudad natal, y acuden a él los recuerdos adolescentes de sus años de colegial. Octavio visita el antiguo refugio donde aprendió los primitivos placeres de su juventud. Allí descubre el trato brutal y la explotación de que es objeto la Nati. Indignado por la violencia que el chulo de ésta ejerce sobre la joven, decide eliminarlo. Pero la Nati al saber que su hombre ha muerto a manos de Octavio, lo insulta y corre a buscar el cuerpo de su brutal amante.

La violencia en este relato se manifiesta en la agresión física de que es objeto la Nati. Los cardenales en su cuerpo, el trato humillante que el bravucón le depara ofenden a Octavio quien se indigna frente a la cobardía del mantenido:

“Cuando llegó hasta ella, advirtió manchas violáceas en las ubres virginales, en el vientre y en las piernas. ¡Una profanación! La devoción del artista cedió a la indignación del hombre:-¿Quién te golpea? -Luisín. -Y ¿por qué? -No te importa...El es mi hombre." 2

La muerte del rufián queda saldada como un asunto entre hombres. En realidad son dos visiones encontradas: para Luisín la Nati es una mercancía, un objeto sexual que produce ganancias y reafirma su hombría y por extensión la del género masculino. Para Octavio en cambio es una hembra destinada al placer pero degradada por la violencia. Lo paradójico en la Nati es su inconciencia que la impele a defender y a llorar la muerte de su agresor y alcahuete.

El desprecio ejercido sobre la Nati y la ignorancia de ésta, nos muestra un espacio en el que la violencia se justifica como norma entre el

${ }^{2}$ Martínez Galindo, Arturo, Cuentos completos, Edición de Oscar Acosta, Editorial Iberoamericana, Tegucigalpa, 1996, Pág. 152. 
chulo y su trata. Octavio retorna a este primitivo universo sin la visión del adolescente; sino como un hombre que antepone un código de valoración: la belleza de la Nati, la sensualidad que de ella emana se puede admirar y poseer, pero no encuentra sentido en la humillación que su tratante le depara. El salvador anónimo de la Nati es un hombre cosmopolita, indignado frente a la brutalidad ejercida sobre esta ingenua criatura. La violencia en el relato procede de Luisín y es generada bajo un código machista. Sin embargo, Octavio acudirá también a la violencia como pretexto para eliminar el amante cobarde de la Nati. Martínez Galindo aún cuando aborda este tema continúa siendo fiel a su estética centrada en la mujer. Es la perspectiva de un escritor insertado en un entorno provinciano y dueño de una atrevida visión para su época. En el tratamiento de personajes y situaciones, la Nati supera su simple condición de prostituta y en la narrativa del autor ella, -como otros tantos personajes femeninos de sus relatosocupa un primer lugar a través de una connotación esteticista y alejándose del realismo estridente y descriptivo de otro autor como Eliseo Pérez Cadalso.

El ensayista Juan Antonio Medina Durón coincide con Salinas Paguada al señalar que Eliseo Pérez Cadalso pertenece a la segunda etapa del regionalismo hondureño, cuando este movimiento ya había perdido fuerza en Hispanoamérica. ${ }^{3}$ Cenizas de Pérez Cadalso contiene relatos donde el autor aborda el tema de la violencia con mayor intensidad que Martínez Galindo. En el cuento Chabelo, por ejemplo, un joven profesor llega a cierta comunidad donde el cruel jefe de la localidad somete a la población. En un gesto de poder y abuso el gendarme advierte al mentor que deberá entregarle la mitad de su salario. El educador es amenazado y expulsado del pueblo por negarse a entregar su estipendio. A solas, Chabelo rememora sus duros días de estudio y los sacrificios sobrellevados para graduarse. Decide ignorar las amenazas presentándose a trabajar. Más tarde es vejado cobardemente por el tirano y huye presa del pánico. Finalmente, en un nuevo encuentro y en un acto de valentía y desesperación mata con sus propias manos a su opresor ${ }^{4}$.

La muerte del criminal a manos de Chabelo coincide con la narrativa

${ }^{3}$ Medina Durón, Juan Antonio, Historia General de la Literatura Hondureña, s.e., s.f., Pág. 50.

${ }^{4}$ Ob. Cit., pp. $9-22$

〈PARADIGMA> - Revista de Investigación Educativa. Año 20. No. 31 
regionalista y de la tierra en Hispanoamérica en las primeras décadas del siglo XX, en la que civilización-desarrollo se enfrenta a naturalezabarbarie. Chabelo encarna el hombre educado enfrentado a la violencia del cacique local. Desde esta perspectiva, la narrativa de Pérez Cadalso es cercana al realismo al recoger las costumbres rurales de una comunidad hondureña de mediados del siglo XX. La violencia en el relato deriva de la injusticia, corrupción y arbitrariedades del representante del gobierno de turno y de todos sus cómplices, quienes actúan contra los habitantes del pueblo. Una vez más la muerte -en este caso del cacique- queda justificada como un asunto de dignidad, ya que Chabelo encarna el deseo de liberación de toda la comunidad contra la opresión local. El tratamiento del tema es directo y registra un hecho muy frecuente entre los pueblos del interior de Honduras. La atmósfera es tensa y de impotencia al mostrarse la imposibilidad de detener la violencia a través de la justicia y la razón. Las descripciones del rufián señalan su condición inhumana que contrasta con la del profesor Chabelo y de la población víctimas de la violencia. Al igual que en el relato de La Nati los protagonistas toman la justicia en sus manos. La historia muestra situaciones y conflictos que reflejan el estado social primitivo y la visión de mundo de una época muy cercana a la dictadura del siglo pasado.

En $\boldsymbol{E}$ l Máusimo la violencia procede de conflictos que emanan entre los personajes y no como el resultado de una agitación social. Es sugerente el apellido Walker en este cuento, que remite en la historia de Centroamérica y en la de Honduras al filibustero William Walker, ya que el padre del Máusimo había sido un vagabundo y era: “(...) un aventurero analfabeto que vino buscando minas y se quedó en la comarca, embrujado por las mujeres, $y,(. .$.$) por la cususa que allí se fabricaba." 5$

El retorno de Máximo Walker altera la calma en el pueblo donde se produce el relato, ya que este personaje, hijo de Walker padre, posee todos los elementos que encarna la violencia: alcohólico, mujeriego, irresponsable, machista y criminal. Máusimo, a quien también le dicen el gringo, tiene por filosofía la fuerza la cual ejerce justificándose en los antecedentes que su padre extranjero le dijo sobre su raza: "Mi tata decía que nosotros somos de sangre superior y que hay que joder a todo el que se ponga por delante." 6

\footnotetext{
${ }^{5}$ Ibídem., 49-50.

${ }^{6}$ Ibídem., 52.
} 
Admirado y temido por la gente de su pueblo, el Máusimo es un personaje en el que se mezcla la ignorancia y la leyenda El cuento adquiere un giro cuando en el pueblo aparecen azoros atribuidos a Delfina o La Prieta, mujer del protagonista. La Prieta no es un simple personaje sin construcción ni historia. Antes de convertirse en la mujer de el Máusimo había sido prostituta en un pueblito cerca de Chinandega, Nicaragua; y el Máusimo, impresionado por su "urbanidad", la lleva a Honduras. Esta presencia de azoros, "cochinadas" o brujerías de La Prieta no llegan a desarrollarse en el relato y se reducen a una anécdota negativa sobre la mujer de el Máusimo; sin embargo, explican la conducta de ésta, puesto que a través de las brujerías La Prieta expresa una ventaja de poder sobrenatural por encima de un mundo en el que los hombres, en este caso el Mausimo, ejercen su voluntad sin límites. En el cuento La Prieta también teme que el Máusimo haya dejado de quererla pues sabe que éste, vive con otra mujer. La promiscuidad y el incesto sirven de ingredientes para que surja la violencia. Ésta, aflora cuando las dos hijas de La Prieta, producto de otros hombres, han crecido y el Máusimo comenta: "-iHumm, ya van a estar de punto...!!!"7

La Prieta alimenta su resentimiento ante las pretensiones de el Máusimo. Imagina el deseo que su hombre siente por Delfina, la única hija que sobrevive en el relato y, como el narrador informa: "Porque las mujeres de su clase -las putas, para decirlo de una vez-son, por paradoja, las madres más desconfiadas y resueltas." 8 El rencor de La Prieta hacia el Máusimo surgirá por dos situaciones; la primera, por dejar de ser la mujer de aquél, y la segunda, por los deseos de el Mausimo de poseer a su hijastra. En el cuento, la violación se consuma como un hecho brutal que concluye con la muerte del Máusimo a manos de La Prieta, y con la salida de ésta hacia la noche donde se perderá inexorablemente. Salida simbólica puesto que La Prieta olvida a su avergonzada hija motivo del ajusticiamiento. La atmósfera del relato es sórdida y destaca las pasiones bajas asís como la irracionalidad de los personajes. El relato posee trazos costumbristas y denuncia una práctica común en el campo y en nuestras ciudades, como sigue siendo el abuso de los padrastros sobre sus hijastras. Pérez Cadalso en este cuento aborda una conducta y un hecho frecuentes en una sociedad estrictamente agraria, la cual, y para la fecha de su

\footnotetext{
${ }^{7}$ Idem., 57.

${ }^{8}$ Idem., 59.
} 
publicación, mostraba este mal que se manifiesta por igual en el campo como en las ciudades, donde muchas veces se encubre por las convenciones sociales.

La Prieta sin embargo es un personaje con mayor sustrato, puesto que, y desde una lectura acorde con la religión católica ella es una bruja al aparecer como una mujer practicante de "puercadas". La Prieta adquiere en el cuento una connotación oscura; es conocedora de maleficios y el narrador nos la muestra como un ser maligno emparentado con la oscuridad. El final del relato reafirma esta idea ya que La Prieta, que en el lenguaje popular es el sobrenombre que se le asigna a una mujer de piel oscura, se perderá en la oscuridad de la noche como si ambas (mujer/noche) estuviesen conformadas de la misma esencialidad. En este sentido bruja, prostituta y mujer "mala" asignan una visión negativa cargada de un fuerte sustrato religioso para caracterizar y marginar a las mujeres que no se sujetaban a una moral cristiana. Fue este un criterio muy extendido en el medioevo y también se aplicó para señalar a las mujeres practicantes de la medicina natural.

Sin embargo La Prieta, bruja y prostituta llena de atributos negativos tomará en sus manos la justicia al decapitar al Mausimo para castigar, de este modo, la violación de su hija. Esta acción, aunque violenta, se traduce en una virtud en ella, puesto que en principio le preocupa el abuso que el Mausimo ejercerá sobre su hija -temor que se llega a cumplir-. Sin embargo, su acción no la libera de su condición maligna: La Prieta se perderá en el telón de fondo del relato sin que su acción de madre-protectora la redima. El relato reafirma, como en la literatura de la tierra antes citada, que los hombres y mujeres del campo son brutales y carentes de leyes. Persiste en esta historia la visión maniqueísta del "homo civilitas" frente a los primitivos habitantes rurales.

El Tunco Crescencio es otro relato ubicado de nuevo en un espacio rural y en el que la violencia adquiere matices complejos. Crescencio regresa a su casa después de huir de la prisión donde cumplía una condena por el asesinato de su esposa. Encuentra su hogar en ruinas $\mathrm{y}$ en un instante rememora las situaciones que lo llevaron a su condición actual: años atrás, obligado a cumplir su plaza en el ejercito, Crescencio regresó un día al sitio que antiguamente fue su feliz hogar. 
Su mujer en aquel entonces lo recibió con frialdad. El protagonista descubrirá más tarde que todo se debe a la infidelidad de su compañera. Un día sorprende a los amantes, mata a su antigua compañera y se enfrenta a duelo con su rival. En la lucha pierde la mano derecha y con la otra asesina a su enemigo. Condenado a diez años de presidio por el doble crímen, Crescencio huye de prisión y regresa a su aldea para encontrar su casa totalmente en ruinas.

En el presente de la historia recuerda el encuentro con un caudillo local, quien lo invitó a sus filas para derrocar al gobierno de turno. En una batalla de las montoneras perdió la otra mano, y quedó con la promesa del General de cerro que una vez en el poder, le traería un par de manos de los Estados Unidos. Más tarde, se entera que quienes pelearon al lado del mílite recibieron pensiones y grados marciales y él absolutamente nada. El personaje reflexiona para concluir, que el producto de su miseria se debió, en gran medida, a su negativa de "arrastrarse" frente a sus superiores; por ello, no le resta más que soñar que otra hubiese sido su suerte.

Para sobrevivir el protagonista elabora con sus hijas cususa o guaro escondidos en el monte. Sin embargo, las leyes del gobierno, por el cual él luchó, prohíben la elaboración clandestina de alcohol y el personaje morirá intentando huir de las autoridades que lo persiguen.

El cuento resume la fracasada existencia de Crescencio cuyo destino escapa a su propia voluntad. De hombre feliz, su vida se modifica con el aparecimiento de los bandos alzados en armas y con el gobierno de turno que le exige el cumplimiento del servicio militar obligatorio. Más tarde, su vida empeorará cuando trabaje para la justicia civil y los nuevos representantes del poder a quienes ha ayudado a ascender. Ningún cambio social ni gobierno lo beneficiará para ayudarlo a salir adelante en su malograda existencia. El relato se queda en un determinismo sin mostrar las causas que originan la tragedia del personaje. La violencia proviene primero de su mujer, luego del Estado, de la justicia, las instituciones y gobernantes de turno quienes reducen a Crescencio a una trágica víctima de la sociedad.

Como lo relata el protagonista al referirse a los primeros años de su matrimonio: "Eramos felices. Verdaderamente felices." 9 Sin embargo 
el paraíso campirano en el que vivió el Tunco Crescencio desaparece frente a la violencia que emana de todo el cuerpo social. El acceso a la justicia no beneficia al protagonista, por el contrario, resulta convertido en una víctima de la corrupción del sistema. El autor muestra que el hombre del campo se encuentra a merced de fuerzas que lo sobrepasan. Fuerzas que emanan de los hombres y de las estructuras sociales que orillan a la desintegración familiar, al crimen y a la marginalidad. El protagonista morirá y su cuerpo será dejado como pasto para las aves de rapiña y el militar resulta el único ganador en esta suerte de miseria humana.

\section{Conclusión}

En conclusión en Arturo Martínez Galindo y en Eliseo Pérez Cadalso la violencia difiere específicamente en el tratamiento de los personajes femeninos. La violencia en el cuento La Nati surge como indignación frente al atropello ejercido por el chulo. Los hechos violentos proceden de personajes masculinos y la mujer conserva su condición pasivaerótica aún cuando las motivaciones de la violencia son estrictamente personales. En cambio, en Pérez Cadalso, el personaje femenino como La Prieta-, deja de ser una simple observadora y frente a la violencia elimina al victimario de su hija al tomar la justicia en sus manos. En los siguientes relatos de Cadalso la violencia se desprenderá de personajes masculinos que lucharán por imponer, cuando pueden, una justicia personal en un contexto sellado por la violencia. En ambos autores la visión social de mundo de quienes emana la violencia es limitada. En Pérez Cadalso los protagonistas a menudo están inmersos en contextos socialmente agitados, sin lograr un distanciamiento crítico y ello se debe a que ambos autores no ahondan en las motivaciones sociales que originan el tema Por ello, se constata un determinismo que subyace en los personajes ya sean hombres o mujeres y la violencia muestra un universo primario donde la razón es inexistente. Estas visiones, coincidenciales en ambos autores, reflejan una sociedad arcaica, agraria y violenta. Los relatos de Eliseo Pérez Cadalso abordan de forma realista este criterio; su regionalismo registra una sociedad que en pleno siglo XX apenas conoce los derechos que otorgan las leyes, el nivel educativo es precario, la miseria material colinda excesivamente con la espiritual, los personajes se rigen por principios de fuerza y los políticos son corruptos, engañan y abusan a los ciudadanos. Eso sí, nuestros autores muestran de fondo 
La violencia en Cuentos completos de Arturo Martínez Galindo y Ceniza de Eliseo Pérez Cadalso

la visión de un mundo en consonancia con un caos donde la violencia se erige como paradigma "natural”. La pregunta sigue siendo: ¿Existe alguna diferencia con lo que acontece en la sociedad hondureña a principios del siglo XXI? 
Emmanuel Jaén

\section{Referencias}

Martínez Galindo, Arturo. Sombra, Imprenta Calderón, honduras, 1940.

Martínez Galindo, Arturo. Cuentos completos, Edición de Oscar Acosta, Editorial Iberoamericana, Honduras, 1996.

Martínez Galindo, Arturo. Cuentos Metropolitanos, Ediciones Guardabarranco, Honduras, 1995.

Medina Durón, Juan Antonio, Historia General de la Literatura Hondureña, s.e., s.f.

Paredes, Rigoberto y Salinas Paguada, Manuel. Literatura Hondureña, editores Unidos, Honduras, 1988.

Pérez Cadalso, Eliseo. Ceniza, Talleres Tipográficos Nacionales, Honduras, 1955. 
La violencia en Cuentos completos de Arturo Martínez Galindo

y Ceniza de Eliseo Pérez Cadalso

\section{Nota del Autor}

Emmanuel Jaén, docente del Departamento de Arte de la Universidad Pedagógica Nacional “Francisco Morazán” en la especialidad de teatro. Cualquier comentario sobre este trabajo favor dirigirlo al correo electrónico jjaensierra@yahoo.com 